\title{
The affordable care act: Past promises, current debates, future directions
}

\author{
Gilbert Berdine MD
}

The Affordable Care Act (ACA) was passed in 2010. This was arguably President Obama's signature piece of legislation and is commonly referred to as Obamacare. As politicians are wont to do, many promises were made. The most infamous promise was, "If you like your health care plan, you can keep it."1 This was so obviously untrue that PolitiFact made it the 2013 Lie of the Year. ${ }^{2}$ This promise was not directed at Medicare beneficiaries, since these people were generally happy with Medicare. Rather this promise was directed at people with employer based private health insurance. It was a promise that was doomed to fail given the structural features of the ACA.

The ACA was sold to the public as health insurance, but it had features that were incompatible with insurance. The ACA was a subsidy to two groups of people. The first group includes those who are insurable but who cannot afford actuarially sound insurance premiums. These would be the working poor and indigent. The second group consists of people who are uninsurable due to pre-existing conditions. Rather than having a risk of medical expenses that can be shared with others with similar risks, they have certain costs that must be paid but exceed their ability to pay.

The only feature that insurance has in common with a subsidy is that beneficiaries pay less in premiums than the costs of a claim. Insurance is able to do this because the risk of a claim is shared among many people. Nobody has to sacrifice anything to pay an insurance claim. A subsidy, on the other hand, must be paid by others who do not receive the benefits. In the case of the ACA, the subsidies are paid from general tax revenue.

Corresponding author: Gilbert Berdine Contact Information: Gilbert.berdine@ttuhsc.edu DOI: $10.12746 /$ swrccc.v6i22.434
Insurance that retains risk stratification has incentives for everyone to minimize their risk as people who take prudent steps to reduce risk qualify for a lower premium commensurate with their reduced risk. An example would be a health insurance policy that offers a reduced premium to non-smokers. Subsidies are received by people who do not see the costs; they have no incentives to reduce risk. This is known as moral hazard. The subsidized only have incentives to qualify for the subsidy. These incentives tend to have perverse economic effects. An example would be someone who is able to work but refuses in order to keep income below some arbitrary threshold to qualify for the subsidy. In some cases the value of the subsidy is greater than the value of the extra income that is declined irrespective of the extra time and effort necessary to earn the extra income.

The two main goals of the ACA were to decrease the number of uninsured people in the U.S. and to lower health care costs. It should have surprised no one that the ACA was successful in the first goal, because subsidies always increase the quantity of transactions, all other things being equal. ${ }^{3}$ The second goal should have been a red flag, however, since subsidies always increase the price, all other things being equal. ${ }^{3}$ President Obama promised multiple times that premiums would decrease by $\$ 2,500$ per year. ${ }^{1}$ While some have argued that insurance premium increases have moderated since the ACA ${ }^{4}$ and others have argued that premium increases have dramatically increased since the ACA ${ }^{5}$ nobody claims that insurance premiums are decreasing.

Figure 1 has important information relevant to the past, present, and future challenges for the ACA. I will return to this figure during discussion of the future trends, but for now, Figure 1 illustrates that health care expenditures are rising for private "insurance" as well as for public programs. Just as subsidies lead to increases in health care prices for Medicare and 


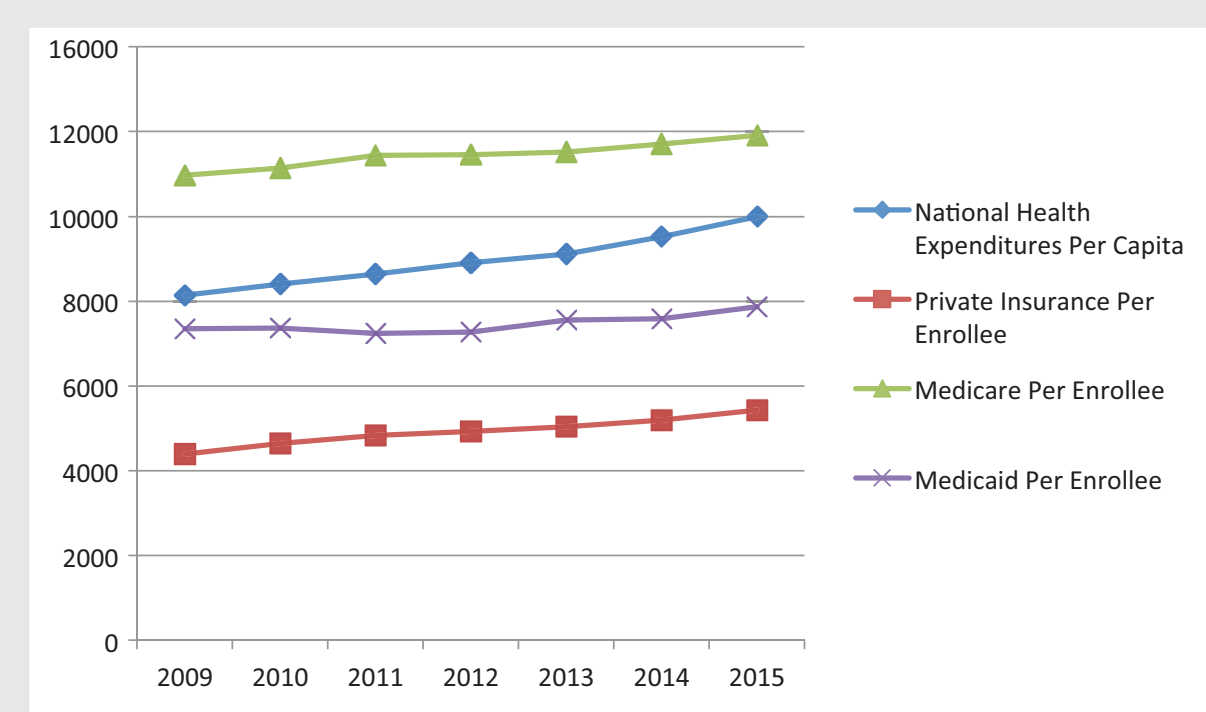

Figure 1. Health expenditure data per capita. Data from Centers for Medicare and Medicaid Services (CMS). ${ }^{6}$

Medicaid, subsidies are responsible for rising health care prices in the so-called private sector. The insurance companies received, until recently, government subsidies to participate in the ACA exchanges. The other form of subsidy is the subsidy for pre-existing conditions. By making risk stratification for pre-existing conditions illegal, the average expected risk is less than the expected risk for those with pre-existing conditions and greater than the expected risk for those without pre-existing conditions. This subsidy from those without pre-existing conditions to those with pre-existing conditions has two major effects on the composition of the risk pool. Those with pre-existing conditions have an incentive to buy insurance at the subsidized rate, but those without pre-existing conditions have an incentive to take their chances without insurance and pay out of pocket for medical expenses as they arise. The Individual Mandate was created to force those without pre-existing conditions to pay higher premiums than were justified for their risk in order to subsidize those with pre-existing conditions. The Individual Mandate has been very unpopular and many have decided to pay penalties rather than buy insurance. ${ }^{7}$ As healthy people opt out, the remaining risk pool has greater risk which leads to higher insurance premiums which escalates the incentive for healthy people to opt out. This is what is known as an insurance death spiral-which is a nice segue into the present state of the ACA debate.

The past year has seen important debates about the ACA. Repeal of the ACA was a major campaign promise by Republicans in general and President Trump in particular. The Republicans failed twice to get enough votes to repeal and replace the ACA. In general the public favors coverage of those with pre-existing conditions; individuals are just not interested in paying for this feature. The public opposes the Individual Mandate. While public support has kept the ACA from being repealed, the funding of the ACA subsidies to insurance companies has been decreased by presidential directive. Furthermore, the recently passed Tax Reform bill repeals the Individual Mandate for the ACA. Even before these changes, insurance companies were leaving the ACA marketplace exchanges. A major story in 2016/2017 was the departure of both Aetna and United Healthcare from the ACA exchange marketplaces. ${ }^{8}$ These departures have left large portions of the U.S. with only one carrier.

Earlier this year, the New York Times claimed that Obamacare was not in a death spiral. ${ }^{10}$ This claim relied on estimates from the Congressional Budget Office (CBO) which assumed no major structural changes going forward. The Washington Post noted 


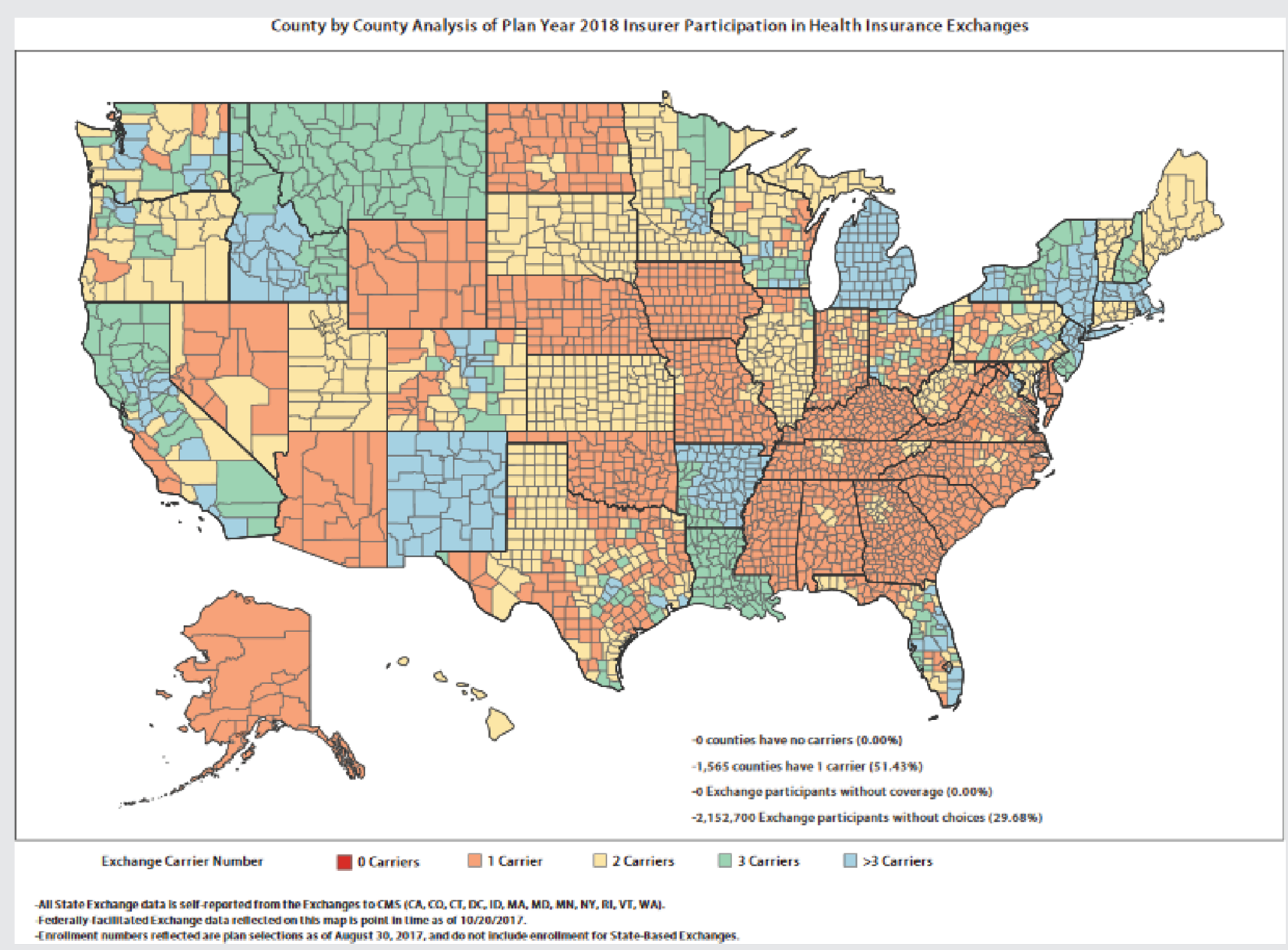

Figure 2. County map of U.S. indicating the number of insurance carriers participating in the ACA marketplace exchanges. Map obtained from CMS. ${ }^{9}$

that elimination of the Individual Mandate could initiate an insurance death spiral and graphically explained how this could happen. ${ }^{11} \mathrm{~A}$ few months ago, President Trump ended subsidies paid to insurance companies used to lower insurance costs for low income people. The New York Times now notes, "Without the subsidies, insurance markets could quickly unravel. Insurers have said they will need much higher premiums and may pull out of the insurance exchanges created under the Affordable Care Act if the subsidies were cut off. Known as cost-sharing reduction payments, the subsidies were expected to total $\$ 9$ billion in the coming year and nearly $\$ 100$ billion in the coming decade."
The death spiral issue is also made more likely by the elimination of the Individual Mandate in the recently passed Tax Reform bill. The future of ACA depends on whether individuals with pre-existing conditions will receive some new form of subsidy.

The possible futures for ACA include some form of repeal and/or replace, an incremental expansion of ACA type subsidized "insurance" exchanges, or some kind of universal coverage. Repeal and/or replace appear to have stalled and are unlikely. The Individual Mandate was eliminated. It seems likely that the debate over ACA will now become a debate over some form of universal coverage. 
The New England Journal of Medicine championed possible futures with universal coverage in a recent issue with two articles, "Which Road to Universal Coverage"13 and "How to Think about Medicare for All." ${ }^{14}$ Neither article deals with the problems of how to pay for these programs. Everyone would prefer to have health care vs. not having health care. Advocates of government subsidized health care either do not realize or do not mention, however, that nobody would prefer having health care vs. having all other possible things. Otherwise, people would voluntarily choose health care over all of their other options and this discussion would be unnecessary. Free health care has unlimited demand; it is a fiscal black hole. Fantasy proposals of universal health care envision a world where everyone is devoting $100 \%$ of their efforts to satisfy the unlimited demands of health. This is a nightmare rather than a utopia. "Which Road to Universal Coverage?" explains away this fiscal problem with a single sentence: "A national health care budget would cap spending on included services." ${ }^{13}$ It is somewhat contradictory that an article on universal coverage describes a "universal" coverage that is capped or limited.

So-called universal coverage is rationing by political means rather than rationing by the market. The market lets individuals decide when they prefer something else vs. the next incremental purchase of health care. Neither "Road to Universal Coverage" nor "Medicare for All" provides details on which services will not be covered or which people will be denied which services. "Which Road to Universal Coverage?" acknowledges that people "would have to believe that the national health budget would selectively purge useless or low-benefit care but not impair beneficial care or advances in medical technology."13 This would indeed be a suspension of disbelief for any health care provider who has spent hours trying to obtain home oxygen or non-invasive ventilation for needy patients when the patient does not fit neatly into one of Medicare's checkboxes. Under universal coverage, rationing decisions would be made by the same people who literally lose billions of dollars ${ }^{15}$ or who were responsible for the VA scandal. ${ }^{16}$

Figure 1 shows another problem with these universal coverage proposals. Government health care systems spend more per patient than private health care systems, yet we are supposed to believe (without any evidence at all) that shifting patients from private care to government care will cost less. Advocates of government subsidized health care never seem to acknowledge that subsidies ALWAYS make goods and services more expensive than they otherwise would be.

The 2017 Medicare Trustees Report has some eye opening figures. ${ }^{17}$ In calendar year 2016, Medicare covered 56.8 million beneficiaries at a cost of $\$ 678.7$ billion ( $\$ 12,829$ per beneficiary). Although the so-called "revenues" to the trust fund are listed at $\$ 710.2$ billion, that revenue figure includes \$319.2 billion transferred from General Revenue. General Revenue is the government budget that is in deficit every year. Medicare is not pay as you go; rather Medicare borrows from the future without any expectation that the loan will ever be repaid.

In 2016, the U.S. spent 17.9 percent of all economic output on health care. ${ }^{6}$ Advocates of universal coverage want this figure to be higher. The problem with these proposals is they offer no mechanism to determine how much is too much. There are no restraints on the production of health care necessary to permit the production of other things.

"Medicare for All" justifies the huge tax increases necessary to pay for the program as a means to address income inequality. "'Medicare' for All offers politicians a way to squarely address the issue. It would lift a substantial financial burden from low and middle-income families-their health insurance premiums-and shift the weight to wealthier Americans by raising their taxes." ${ }^{14}$ This is naïve. Public financing is necessary for pharmaceutical and other health care corporations to charge outrageous prices for goods and services while still getting paid. ${ }^{18}$ Medicare for all will enable these same corporations to impoverish the working poor and middle class with crushing tax burdens so as to pay an ever increasing price for an ever decreasing quality of monopoly health care. Medicare for all would essentially convert every health care corporation into a cost plus rent seeking defense contractor. 
The financial burdens of health care may be already taking a toll on working people. The CDC recently released data showing that life expectancy declined in the United States for the last two years with data (2015 and 2016). ${ }^{19}$ This is very unusual for a developed country in the absence of war or some pandemic. These data also show that mortality rates increased for every age group between 15 and 64 while mortality decreased for every age group 65 and over. Subsidized health care does not seem to be working out well for those who have to pay the subsidies. While the causes for decreased life expectancy in developed countries is most likely multi-factorial, subsidized health care leads to fewer jobs available as manufacturers move to countries without health care taxes. For those who are fortunate to find jobs, subsidized health care taxes away a greater percentage of stagnant wages leaving less available for individual choices.

The ACA started with a promise-health insurance premiums will cost less-that could not possibly be kept. As the advocates of government subsidized health care forget the failings of ACA and set their sights on Universal Coverage, we should be mindful that these promises of affordability will not be kept either.

Keywords: Affordable care act, Medicare, insurance, subsidies

From: Department of Internal Medicine, Texas Tech University Health Sciences Center, Lubbock, TX

Submitted: $12 / 11 / 2017$

Accepted: 1/10/2018

Reviewer: Melvin Laski MD, Neil Kurtzman MD

Conflicts of interest: none

\section{REFERENCES}

1. 7 Key Promises Obamacare Broke. 2017, at http://www.dailywire.com/news/14725/7-key-promises-obamacare-brokeaaron-bandler

2. Lie of the Year: 'If you like your health care plan, you can keep it'. 2013, at http://www.politifact.com/truth-o-meter/ article/2013/dec/12/lie-year-if-you-like-your-health-careplan-keep-it/
3. Berdine, Gilbert. "Supply and Demand: Government Interference with the Unhampered Market in U.S. Health Care." The Southwest Respiratory and Critical Care Chronicles [Online], 2.7 (2014): 21-24. Web. 10 Jan. 2018.

4. No, Obamacare Hasn't Jacked Up Your Company's Insurance Rates. 2017, at https://www.forbes.com/sites/ robbmandelbaum/2017/02/24/no-obamacare-hasnt-jackedup-your-companys-insurance-rates/\#5bfa5493a016

5. Yes, It Was The 'Affordable' Care Act That Increased Premiums. 2017, https://www.forbes.com/sites/theapothecary/2017/03/22/ yes-it-was-the-affordable-care-act-that-increased-premiums/ \#7b06f3e011d2

6. CMS.gov Centers for Medicare and Medicaid Services. 2016, at https://www.cms.gov/Research-Statistics-Data-andSystems/Statistics-Trends-and-Reports/NationalHealth ExpendData/NationalHealthAccountsHistorical.html

7. Ballotpedia.2017, athttps://ballotpedia.org/Scott_Rasmussen \%27s_Number_of_the_Day_for_August_9_2017

8. One-third of U.S. could see only one Obamacare option as insurers pull out. 2016, https://www.washingtontimes. com/news/2016/aug/29/aetna-unitedhealth-pulling-out-ofobamacare-leavin/

9. CMS.gov Centers for Medicare and Medicaid Services. 2018, at https://www.cms.gov/CCIIO/Programs-and-Initiatives/ Health-Insurance-Marketplaces/Downloads/2017-10-20-IssuerCounty-Map.pdf

10. No, Obamacare Isn't in a 'Death Spiral'. 2017, at https:// www.nytimes.com/2017/03/15/upshot/obamacare-isnt-in-adeath-spiral-its-replacement-probably-wont-be-either.html

11. How the Senate bill could send the health insurance market into a death spiral. 2017, at https://www.washingtonpost. com/news/wonk/wp/2017/06/23/republicans-say-the-healthinsurance-market-is-in-a-death-spiral-their-bill-couldmake-it-really-happen/

12. Trump to Scrap Critical Health Care Subsidies, Hitting ObamacareAgain.2017, athttps://www.nytimes.com/2017/10/12/ us/politics/trump-obamacare-executive-order-healthinsurance.html

13. Aaron, $\mathrm{H}$. Which Road to Universal Coverage?. N Engl J Med 2017 Dec 17:377(23):2207-09. http://www.nejm.org/ doi/pdf/10.1056/NEJMp1713346

14. Morone, J. How to Think about "Medicare for All". N Engl J Med 2017 Dec 17:377(23):2209-11 http://www.nejm.org/ doi/pdf/10.1056/NEJMp1713510

15. How the US sent $\$ 12 \mathrm{bn}$ in cash to Iraq. And watched it vanish. 2007, at https://www.theguardian.com/world/2007/ feb/08/usa.iraq1

16. 'Vets continue to die': Phoenix hospital at center of VA scandal ranked among nation's worst. 2017, at http://www. foxnews.com/us/2017/02/09/vets-continue-to-die-phoenix- 
hospital-at-center-va-scandal-ranked-among-nations-worst. html

17. CMS.gov Centers for Medicare and Medicaid Services. 2017, at https://www.cms.gov/Research-Statistics-Data-andSystems/Statistics-Trends-and-Reports/ReportsTrustFunds/ Downloads/TR2017.pdf
18. Data Brief 293 Tables: Mortality in the United States. 2016 at https://www.cdc.gov/nchs/data/databriefs/db293_table. pdf\#1

19. Why Some Pharmaceuticals Are So Expensive. 2017, at https://mises.org/blog/why-some-pharmaceuticals-are-soexpensive 